IJBM

39,1

Received 18 March 2020 Revised 31 July 2020 20 September 2020 Accepted 22 September 2020

\section{Measuring financial well-being in Europe using a fuzzy set approach}

\author{
Antonella D’Agostino, Monica Rosciano and Maria Grazia Starita \\ Department of Mangement and Quantitative Studies, \\ University of Naples-Parthenope, Naples, Italy
}

\begin{abstract}
Purpose - This paper aims to apply a multidimensional approach to assessing the financial well-being of European countries.

Design/methodology/approach - Financial well-being is a very complex phenomenon to measure because it is composed of different dimensions. Therefore, this paper uses a multidimensional and fuzzy methodology to assess financial well-being in Europe. The financial well-being fuzzy indicator was calculated using European Quality of Life Survey data.

Findings - Financial well-being is heterogeneous across European countries. This evidence is confirmed both at the level of overall financial well-being and at the level of sub-indices. The degree of financial well-being is not directly related to wealth as traditionally measured (i.e. GDP), but shows some correspondence with socioeconomic characteristics of the population and with governance and cultural elements of a country.

Practical implications - Understanding financial well-being could help financial institutions to transition from a one-size-fits-all approach to a more tailored approach when they provide financial services and could help policy makers to consider financial well-being when they decide how and where to allocate public spending.
\end{abstract}

Originality/value - To the best of authors' knowledge, this study is the first to employ a fuzzy methodology for the analysis of financial well-being in Europe.

Keywords Financial well-being, Dimensions of financial well-being, Multidimensional and fuzzy set approach, Europe

Paper type Research paper

\section{Introduction}

In recent years, financial well-being $(\mathrm{FW})$ has been the subject of a lively debate. The dramatic decrease in household savings rates for most industrialized countries during the financial crisis (IMF, 2014) gives rise to a number of economic questions about how consumers can effectively invest their savings, especially if they belong to vulnerable groups, to maintain or increase their quality of life and financial expectations for retirement.

Currently, FW studies are found in different fields of research (e.g. subjective well-being, consumer finance and transformative services) and are of interest to different authorities (e.g. Consumer Financial Protection Bureau (CFPB) for USA, Financial Conduct Authority (FCA) for UK). However, there is no common agreement about how FW can be defined and measured (Brüggen et al., 2017; Kabadayi and O'Connor, 2019). Among other researchers, ComertonForde et al. (2018) highlighted the importance of studying FW from a multidimensional perspective because of its multifaceted nature. In this paper, we stress the importance of considering the multidimensional nature of FW by defining it as the combination of different dimensions discussed in the available literature. Moreover, we also implement a fuzzy set approach (Betti et al., 2016) that efficiently summarizes this multidimensional aspect by incorporating the idea that FW manifests itself in different degrees.

(c) Antonella D’Agostino, Monica Rosciano and Maria Grazia Starita. Published by Emerald Publishing Limited. This article is published under the Creative Commons Attribution (CC BY 4.0) licence. Anyone may reproduce, distribute, translate and create derivative works of this article (for both commercial and non-commercial purposes), subject to full attribution to the original publication and authors. The full terms of this licence may be seen at http://creativecommons.org/licences/by/4.0/legalcode 
We based our empirical analysis on the European Quality of Life Survey to assess FW in Europe. The empirical analysis suggests three major results: (1) FW is heterogeneous across European countries; (2) the degree of FW is not directly related to wealth as traditionally measured; and (3) the socio-economic and demographic characteristics, as well as the governance and cultural framework, influence the degree of FW. The contribution of this study to the empirical literature should be read in the following way: our purpose is to broaden the discussion of the crucial topic of FW in Europe, adding some interesting points to the current literature. First, the fuzzy approach we propose for measuring FW represents a simple tool that can be used in this multidimensional framework to preserve the richness of the available information. Second, we compute the FW indicator using a large-scale survey that collects information on the quality of life; in so doing, we expand the range of the application of the survey itself. Third, there is no other evidence on the assessment of FW in Europe.

Our results provide new insights for policy makers and financial institutions. Policy makers should consider FW together with health, environment, job and social relationships to analyze the happiness or satisfaction of their own people when using public spending. Finally, understanding $\mathrm{FW}$ could become an instrument to allow financial institutions to pass from a one-size-fits-all approach to a more tailored approach when they provide a financial service.

The rest of this paper is organized as follows. Section 2 reviews previous research. Section 3 describes how we define FW. Section 4 shows the data, variables and fuzzy methodology. Section 5 presents our results. Finally, in the last section, we discuss the results and the conclusion, including practical implications, limitations and directions for future research.

\section{Literature review}

The debate on the dramatic decrease in savings for most industrialized countries during the financial crisis (IMF, 2014) has increased the attention directed toward other measures of financial decision-making, such as FW. Starting from the seminal paper of Van Praag et al. (2003) that conceptualizes subjective well-being and the role of other domains of general satisfaction, the literature is sizeable until it reaches the research agenda of Brüggen et al. (2017). Indeed, academics in various fields of research (e.g. subjective wellbeing, consumer finance and transformative services) have analyzed FW. For example, some scholars have focused their attention on both objective and subjective characteristics of FW (Shim et al., 2009) or on subjective characteristics (Aggarwal, 2014), rather than on objective characteristics (Greninger et al., 1996). Other scholars have analyzed the role of non-cognitive drivers that lead to suboptimal financial decision-making (e.g. Estelami, 2009, and, more recently, Florendo and Estelami, 2019) or of other elements that are strictly related to FW, such as financial education or financial capability (e.g. Xiao and Porto, 2017). As highlighted by the CFPB (2015), personal attitude, non-cognitive skills, and personality factors - called personal traits - exercise a direct influence on financial capability and play a role in the transmission of factual knowledge ("knowing how to do") into financial behavior, which translates over into FW From the point of view of policy makers, the ability to manage personal finance and cope with financial shocks has always been important (e.g. Muir et al., 2017). Today, due to the increasing complexity of the financial system, achieving FW at the individual and societal levels can be a problem. Several financial education initiatives have been carried out (for a survey, see Kempson et al., 2017), but the attempts of policy makers in this direction have been met with many obstacles from what people actually $d o$ rather than what people know (Kempson et al., 2017; Muir et al., 2017). More specifically, people could be capable in one domain of financial behavior and not in others at the same time. These issues are enhanced by the lack of common agreement about what FW is and what it is not. For example, Prawitz

Measuring financial well-being 
IJBM 39,1

et al.'s (2006) definition spans from how satisfied an individual is with her or his present financial situation to how stressed does she or he feel about her or his personal finances in general, whereas Netemeyer et al.'s (2018) definition is focused on the difference between "How am I doing today?" and "How do I expect I will be doing in the future?," as the antecedents of current money management stress are different from the antecedents of expected future financial security. Even if $\mathrm{FW}$ has not been analyzed to date in the international comparison of the Organization for Economic Co-operation and Development (OECD) financial literacy survey data, Riitsalu and Murakas (2019) use four OECD questions to measure $\mathrm{FW}$ in their research.

From a methodological point of view, FW cannot be considered to be a monolith, but rather to be a multifaceted construct (e.g. Abrantes-Braga and Veludo-de-Oliveira, 2019) that is not directly observable (Comerton-Forde et al., 2018.). Indeed, FW is perceived (Prawitz et al., 2006; Netemeyer et al., 2018; Ponchio et al., 2019; Chatterjee et al., 2019); it is relative (Brüggen et al., 2017); it is linked to the living standard (Arber et al., 2014; Brüggen et al., 2017; Netemeyer et al., 2018) and to financial freedom (Taylor et al., 2009, 2011; CFPB, 2015; Brüggen et al., 2017); and it has a time dimension (Netemeyer et al., 2018; Ponchio et al., 2019). These premises suggest treating FW as a multidimensional phenomenon.

\section{Conceptualizing financial well-being as a multidimensional and fuzzy concept}

As explained in the previous section, several researchers of $\mathrm{FW}$ have stressed the importance of studying FW from a multidimensional perspective (e.g. Comerton-Forde et al., 2018). To study this topic further, we define $\mathrm{FW}$ as the combination of the following five dimensions: (1) inner well-being $(I W)$, (2) relative assessment $(R A)$, (3) time $(T D)$, (4) financial security $(F S)$ and (5) financial freedom $(F F)$. From an empirical point of view, the direct measurement of such dimensions is not easy because each of them is indeed the combination of a number of observable indicators that refer to several aspects linked to the literature quoted in the previous section. FW is subjective in nature "because it is based on how an individual perceives it rather than how it is objectively denoted" (Brüggen et al., 2017, p. 230). Empirical questions that measure satisfaction, happiness and the psychological status of the respondent are correlated and can measure how FW is perceived. FW is relative (Brüggen et al., 2017). FW assessments change relative to a person's social reference groups and are relative in comparison with the individual's personal life goals (CFPB, 2015; Muir et al., 2017). Therefore, items that measure the perceived comparison with society and with oneself are useful to represent the relative assessment of FW. FW has a time dimension (Netemeyer et al., 2018). FW is related to time in two ways: it depends on current and future situations and it is dynamic because individuals' evaluations of their subjective FW can change over time. This facet of FW could be captured by questions about the comparison of the individual's actual financial situation with the past and with expectations for the future. FW is related to living standards (Arber et al., 2014; Brüggen et al., 2017). In particular, the desired living standard refers to "how someone would prefer his or her quality of life to be" (Brüggen et al., 2017, p. 230). Useful questions to measure this dimension of well-being may be, for example, those relating to one's ability or inability to make ends meet or pay one's debt by or after the deadline. FW is related to financial freedom (Taylor et al., 2011; CFPB, 2015; Brüggen et al., 2017): "Having financial freedom enables individuals to make life decisions without worrying about financial constraints, and achieving it would improve that person's perception of having financial well-being" (Brüggen et al., 2017, p. 230). Questions about the things that many people can or cannot afford, even if they would like them, could measure financial freedom.

On the other hand, the literature on the methodological tools for summarizing multidimensional concepts is very large, and the process depends on the aim of the 
analysis. When the scope of the research is to combine multidimensional information to obtain a single index, the background literature refers to composite indicators (Greco et al., 2019; Grupp and Mogee, 2004). Various methodologies have been developed to handle different issues related to the empirical implementation of composite indicators, depending on the field of analysis (Kaklauskas et al., 2018; Giambona and Vasallo, 2014; Bandura, 2011). In this paper, we refer to the literature linked to the measurement of well-being using a multidimensional and fuzzy approach (see, among others, Betti et al., 2020a; D'Agostino et al., 2019). We, therefore, propose to synthetize these five dimensions using a composite indicator that measures financial well-being overall. The advantage of using a fuzzy approach is that it summarizes in an efficient way the multidimensional aspect of $\mathrm{FW}$ by incorporating the idea that FW manifests itself in different degrees. Indeed, the main literature in the field recognizes that $\mathrm{FW}$ is a measure that attempts to reflect values between a theoretical minimum (no FW) and maximum (complete FW). For example, the CFPB FW scale is truly continuous, whereas the Netemeyer et al. (2018) scale is a sum of scores built from Likert responses.

\section{Methods}

\section{Data and variables}

To compute the fuzzy FW indicator, we use data collected in the Third European Quality of Life Survey (i.e. EQLS3) of the European Foundation for the Improvement of Living and Working Conditions (Eurofound), which took place in 2011-2012. The EQLS records many aspects of the quality of life in Europe, including social, economic, environmental and workrelated elements, especially life satisfaction and the perceived quality of society (Anderson et al., 2012).

The target population of the survey is all residents of the 27 European Union (EU) member states (Austria, Belgium, Bulgaria, Cyprus, Czech Republic, Denmark, Estonia, Finland, France, Germany, Greece, Hungary, Ireland, Italy, Latvia, Lithuania, Luxembourg, Spain, Malta, The Netherlands, Poland, Portugal, Romania, Slovakia, Slovenia, Sweden, the UK) and seven non-EU countries (Croatia, Iceland, Kosovo, the Former Yugoslav Republic of Macedonia, Montenegro, Serbia and Turkey) aged 18 or older. The UK is considered in Europe because the data were collected before Brexit.

In this paper, we focus on individuals between 25 and 65 years old. Young adults are excluded because they are in an age group characterized by frequent change and exploration (Rindfuss, 1991; Arnett, 2000). During this time, many young people obtain the level of education and training that will provide the foundation for their incomes and occupational achievements for the remainder of their adult working lives (Chisholm and Hurrelmann, 1995). Even though some studies in the financial literature are devoted to analyzing the needs and financial perspectives of people over 65 years old (Zurlo, 2009; Figari et al., 2011; LaRochelle-Côté, 2012; Piumatti, 2017), we do not consider these oldest people, though it could be an interesting target population to analyze in the future.

There are 29,871 individuals in the age group 25-65 in our sample, and they represent, on average, $69 \%$ of the total sample size. In particular, this percentage ranges from $60 \%$ in Lithuania to $75 \%$ in Turkey (Table A1). After eliminating observations with missing values, the sample size decreases to 28,239 individuals.

The selection process for the items used to compute the fuzzy FW indicator involves selecting those questions from the survey related to the dimensions of FW suggested by the literature and discussed in Section 2. Ultimately, we processed a set of 39 observable indicators. In Table 1, we present the selected indicators organized along the five dimensions previously defined in Section 3. This theoretical structure has been confirmed and discussed in the section related to results. 


\section{IJBM 39,1}

52

\begin{tabular}{|c|c|c|c|}
\hline FW dimension & $\begin{array}{l}\text { EQLS } \\
\text { question code }\end{array}$ & $\begin{array}{l}\text { Item } \\
\text { number }\end{array}$ & EQLS question \\
\hline $\begin{array}{l}\text { Inner well-being } \\
(I W)\end{array}$ & Q30 & Item1 & $\begin{array}{l}\text { All things considered, how satisfied would you say you are } \\
\text { with your life these days? }\end{array}$ \\
\hline \multirow[t]{13}{*}{$\begin{array}{l}\text { Cronbach alpha } \\
0.88\end{array}$} & Q40c & Item2 & $\begin{array}{l}\text { How satisfied you are with your present standard of } \\
\text { living? }\end{array}$ \\
\hline & Q40d & Item3 & How satisfied you are with your accommodation? \\
\hline & Q40h & Item4 & $\begin{array}{l}\text { How satisfied you are with economic situation in } \\
\text { (COUNTRY)? }\end{array}$ \\
\hline & Q41 & Item5 & How happy would you say you are? \\
\hline & Q42 & Item6 & In general, would you say your health is? \\
\hline & Q45a & Item7 & I have felt cheerful and in good spirits \\
\hline & $\mathrm{Q} 45 \mathrm{~b}$ & Item8 & I have felt calm and relaxed \\
\hline & $\mathrm{Q} 45 \mathrm{c}$ & Item9 & I have felt active and vigorous \\
\hline & Q45d & Item10 & I woke up feeling fresh and rested \\
\hline & Q45e & Item11 & My daily life has been filled with things that interest me \\
\hline & Q46a & Item12 & I have felt particularly tense \\
\hline & Q46b & Item13 & I have felt lonely \\
\hline & $\mathrm{Q} 46 \mathrm{c}$ & Item14 & I have felt downhearted and depressed \\
\hline Relative & Q29b & Item15 & I generally feel that what I do in life is worthwhile \\
\hline assessment (RA) & Q29e & Item16 & I feel left out of society \\
\hline Cronbach alpha & Q29g & Item17 & I feel that the value of what I do is not recognized by others \\
\hline \multirow[t]{3}{*}{0.65} & Q29h & Item18 & $\begin{array}{l}\text { Some people look down on me because of my job situation } \\
\text { or income }\end{array}$ \\
\hline & Q29i & Item19 & I feel close to people in the area where I live \\
\hline & Q57 & Item 20 & $\begin{array}{l}\text { Could you please evaluate the financial situation of your } \\
\text { household? In comparison to most people in (COUNTRY) }\end{array}$ \\
\hline \multirow{4}{*}{$\begin{array}{l}\text { Time dimension } \\
\text { (T) } \\
\text { Cronbach alpha } \\
0.56\end{array}$} & Q29a & Item21 & I am optimistic about the future \\
\hline & Q65 & Item22 & When you compare the financial situation of your \\
\hline & & & $\begin{array}{l}\text { household } 12 \text { months ago and now, would you say it has } \\
\text { become better, worse or remained the same? }\end{array}$ \\
\hline & Q66 & Item23 & $\begin{array}{l}\text { When it comes to the financial situation of your household, } \\
\text { what are your expectations for the } 12 \text { months to come, will } \\
\text { the next } 12 \text { months be better, worse or the same? }\end{array}$ \\
\hline \multirow{8}{*}{$\begin{array}{l}\text { Financial security } \\
\text { (FS) } \\
\text { Cronbach alpha } \\
0.67\end{array}$} & Q20 & Item24 & $\begin{array}{l}\text { How likely or unlikely do you think it is that you will need } \\
\text { to leave your accommodation within the next } 6 \text { months }\end{array}$ \\
\hline & 025 & Item 25 & because you can no longer afford it? \\
\hline & Q35e & Item 25 & $\begin{array}{l}\text { From whom would you get support it you needed to } \\
\text { urgently raise? }\end{array}$ \\
\hline & Q58 & Item26 & $\begin{array}{l}\text { Thinking of your household's total monthly income: is } \\
\text { your household able to make ends meet? }\end{array}$ \\
\hline & Q60a & Item27 & $\begin{array}{l}\text { Has your household been in arrears at any time during the } \\
\text { past } 12 \text { months, i.e. unable to pay rent or mortgage } \\
\text { payments for accommodation? }\end{array}$ \\
\hline & Q60b & Item28 & $\begin{array}{l}\text { Has your household been in arrears at any time during the } \\
\text { past } 12 \text { months, i.e. unable to pay utility bills, such as } \\
\text { electricity, water, gas? }\end{array}$ \\
\hline & Q60c & Item29 & $\begin{array}{l}\text { Has your household been in arrears at any time during the } \\
\text { past } 12 \text { months, i.e. unable to pay payments related to } \\
\text { consumer loans, including credit card overdrafts (to buy } \\
\text { electrical appliances, a car, furniture, etc.)? }\end{array}$ \\
\hline & Q60d & Item30 & $\begin{array}{l}\text { Has your household been in arrears at any time during the } \\
\text { past } 12 \text { months, i.e. unable to pay payments related to } \\
\text { informal loans from friends or relatives not living in your } \\
\text { household? }\end{array}$ \\
\hline
\end{tabular}

(continued)

Table 1.

FW dimensions and items selected from EQLS3 


\begin{tabular}{|c|c|c|c|c|}
\hline FW dimension & $\begin{array}{l}\text { EQLS } \\
\text { question code }\end{array}$ & $\begin{array}{l}\text { Item } \\
\text { number }\end{array}$ & EQLS question & \multirow{2}{*}{$\begin{array}{l}\text { Vleasuring } \\
\text { financial } \\
\text { well-being }\end{array}$} \\
\hline \multirow{9}{*}{$\begin{array}{l}\text { Financial } \\
\text { freedom (FF) } \\
\text { Cronbach alpha } \\
0.77\end{array}$} & Q29c & Item31 & I feel I am free to decide how to live my life & \\
\hline & Q29d & Item32 & $\begin{array}{l}\text { In my daily life, I seldom have time to do the things I really } \\
\text { enjoy }\end{array}$ & \\
\hline & Q29f & Item33 & $\begin{array}{l}\text { Life has become so complicated today that I almost cannot } \\
\text { find my way }\end{array}$ & 53 \\
\hline & Q59a & Item34 & $\begin{array}{l}\text { There are some things that many people cannot afford, } \\
\text { even if they would like them. Keeping your home } \\
\text { adequately warm }\end{array}$ & \\
\hline & Q59b & Item35 & $\begin{array}{l}\text { There are some things that many people cannot afford, } \\
\text { even if they would like them. Paying for a week's annual } \\
\text { holiday away from home (not staying with relatives) }\end{array}$ & \\
\hline & Q59c & Item36 & $\begin{array}{l}\text { There are some things that many people cannot afford, } \\
\text { even if they would like them. Replacing any worn-out } \\
\text { furniture }\end{array}$ & \\
\hline & Q59d & Item37 & $\begin{array}{l}\text { There are some things that many people cannot afford, } \\
\text { even if they would like them. A meal with meat, chicken, } \\
\text { fish every second day if you wanted it }\end{array}$ & \\
\hline & Q59e & Item38 & $\begin{array}{l}\text { There are some things that many people cannot afford, } \\
\text { even if they would like them. Buying new, rather than } \\
\text { second-hand, clothes }\end{array}$ & \\
\hline & Q59f & Item39 & $\begin{array}{l}\text { There are some things that many people cannot afford, } \\
\text { even if they would like them. Having friends or family for a } \\
\text { drink or meal at least once a month }\end{array}$ & Table 1. \\
\hline
\end{tabular}

\section{Fuzzy set approach}

We apply the statistical methodology proposed by Betti et al. (2016) to study quality of life. The universal and interdisciplinary nature of this approach has been revised in Betti et al. (2020b), where the authors examine previous writings (among others, Betti et al., 2006) and attempt to develop an understanding of the role this methodology could play in defining composite indicators in several empirical settings. The main feature of this approach is that the phenomena under study are multidimensional, not directly observable (i.e. composed of latent dimensions), and fuzzy. Accordingly, $\mathrm{FW}$ is composed of a set of latent dimensions: what we observe instead is a number of indicators (as listed in Table 1) that represent the specific dimensions described in the previous section.

As Betti et al. (2020a) explain, the latent dimensions of the phenomena under study are not predefined $a$ priori, but they are identified by exploratory factor analysis (EFA) and then validated by confirmatory factor analysis (CFA) (Kline, 2005). Therefore, in this approach, factor analysis is used to validate the hypothesized structure of the theoretical framework. Moreover, the authors stress that the aggregation of single indicators into the corresponding dimension is performed by a statistical-based weighting system that takes into account measurement errors, redundancies and other characteristics of such indicators. In other words, the weighting system follows a "prevalence-correlation" (i.e. taking into account both the dispersion of a single indicator (prevalence weights) and its correlation with the other indicators in a given dimension (correlation weights)).

Let $y k(j=k \ldots K)$ be the $k$ th indicator listed in Table 1 . These $k$ indicators are grouped into the following five dimensions: (1) the inner well-being dimension $(I W)$, (2) the relative assessment dimension $(R A),(3)$ the time dimension $(T D)$, (4) the financial security dimension $(F S),=$ and $(5)$ the financial freedom dimension $(F F)$. 
IJBM 39,1

These indicators are first converted into scores in the $[0,1]$ interval. Let $c_{j}\left(j=1 \ldots C_{j}\right)$ be the category of each indicator, with $k$ being ordered from the lowest value of $\mathrm{FW}$ to the highest. To convert each indicator $k$ into the $[0,1]$ interval, we use the following transformation:

$$
d_{j, i}=\frac{F\left(c_{j, i}\right)-F(1)}{F\left(C_{j}\right)-F(1)}, j=1 \ldots K, i=1 \ldots n
$$

where $c_{j, i}$ is the category of the $k$ th indicator, corresponding to the $i$ th $(i=1 \ldots n)$ individual, and $F\left(c_{j, i}\right)$ is the corresponding cumulation function. When the indicator assumes a value equal to one (lowest level of $\mathrm{FW}$ ), then $F\left(c_{j, i}\right)=F(1)$, and the score is equal to zero. Instead, when the indicator assumes the highest level of $\mathrm{FW}$ (e.g. $C_{j}$ ), then the numerator of equation (1) is equal to the denominator, and the score is equal to one.

In the second step, we use CFA to confirm the hypothesized structure of the five latent dimensions (Whelan et al., 2001). Then, a membership function with values in the [0,1] interval is defined for each FW dimension; this function is a quantitative specification of individual levels of FW. Accordingly, the membership function's value of 0 is always associated with the lowest level of $\mathrm{FW}$, and a value of 1 is associated with the highest level. Membership function values between 0 and 1 indicate intermediate levels of FW.

As a membership function is defined for each FW dimension, for the sake of simplicity, let $s\left(s=\right.$ IW, RA, TD, FS, FF) be one of the five dimensions of FW and letFW ${ }_{(S)}$ be its corresponding membership function. Each dimension $s$ is composed of a different number of single indicators previously transformed using equation (1). Each membership function is defined separately for each country. Therefore, if $\mathrm{FW}_{(s) i}=1$, then the $i$ th individual has the highest level of $\mathrm{FW}$, whereas if $\mathrm{FW}_{(s) i}=0$, then the $i$ th individual has the lowest level of $\mathrm{FW}$. Accordingly, as the values increase from 0 to 1 , the $\mathrm{FW}$ of the $i$ th individual for the corresponding dimension increases. Formally, to obtain FWsi, a first aggregation over the set of single $d_{j, i}$ scores in the particular dimension $s$ is made as follows:

$$
\mathrm{FW}_{(S) i}=\sum_{k} \frac{w_{(s) k} d_{(s) j i}}{\sum_{k} w_{(s) k}}
$$

where $W_{(S) k}$ is the weight of the $k$ th single indicator in the $s$ th dimension, computed as $W_{(S) k}=W_{(s) k}^{a} * W_{(s) k}^{b}$. The first factor is the prevalence weight, and the second is the correlation weight (Betti and Verma, 2008). A comprehensive measure of the FW of each individual $i$ in each country is obtained as the unweighted mean over the five dimensions of $\mathrm{FW}_{(s)}$, i.e.:

$$
\mathrm{FW}_{(\text {OVERALL)i }}=\frac{\sum_{s} \mathrm{FW}_{(s) i}}{5}
$$

The (sample) weighted means $\left(\overline{\mathrm{FW}}_{(I W)}, \overline{\mathrm{FW}}_{(R A)}, \overline{\mathrm{FW}}_{(T D)}, \overline{\mathrm{FW}}_{(F S)}, \overline{\mathrm{FW}}_{(F F)}\right.$ and $\left.\overline{\mathrm{FW}}_{\text {OVERALL }}\right)$ of these individual values in equations (1) and (2) give measures of the degree of $\mathrm{FW}$ observed at the country level in each dimension $s$ and for all dimensions as whole.

\section{Results}

The first finding is that the data support the conceptual framework described in the previous section.

Indeed, we test the capacity of the 39 selected items to describe the five different latent dimensions of FW (IW, RA, TD, FS and FF). The Cronbach's alpha indices, reported in Table 1, confirm a good level of internal consistency and reliability of the scales as a whole in four out of the five dimensions (Cronbach, 1951; Taber, 2018). Indeed, the reliability of each 
scale item ranges from $0.56-0.88$. Second, we use EFA to derive an operating framework according to a mechanistic approach that leaves out the theoretical assumptions. This analysis mostly supports our null hypothesis. Indeed, we identify the previously supposed five dimensions, except for a few items. Using the results of this framework, we proceed to rearrange these items in the assumed dimensions to create more meaningful groups. Finally, we use CFA to confirm the overall assessment of the final theoretical framework by pooling all the countries together. In other words, we test whether relationships between the observed items and their underlying latent constructs (dimensions) exist. While there is no golden rule for the assessment of model fit, reporting a variety of indices is necessary because different indices reflect different aspects of model fit. Among others, Hoyle and Panter (1995) present guidelines for reporting information regarding CFA model fitting. The root mean square error of approximation (RMSEA) expresses the unexplained or residual variance of the factor structure; it is equal to 0.072 . Values of this statistic between 0.05 and 0.08 indicate reasonable errors of approximation in the population. Furthermore, we compute the standardized root mean square residual (SRMR). A rule of thumb is that the SRMR should be less than 0.05 for a good fit (Hu and Bentler, 1995), whereas values between 0.05 and 0.10 may be interpreted as acceptable. We observe an SRMR equal to 0.08 .

The main results are summarized in Table 2. Each value in Table 2 represents the degree of FW with respect to the specific dimension (IW, RA, TD, FS and FF) and overall (FW) at the country level. A value of 0 implies the lowest degree of $\mathrm{FW}$, whereas a value of 1 is associated with the highest degree of $\mathrm{FW}$.

$\mathrm{FW}_{\text {OVERALL }}$ spans from $0.56-0.69$. To test if there are significant differences across countries, we implement a non-parametric Dunn's test (Dinno, 2015), which allows multiple non-parametric pairwise comparisons of independent groups and is therefore a useful tool for validating our findings (Table A2). It is worth noting that the use of this non-parametric test is bounded by the strong non-normality of fuzzy measures. Nevertheless, it is also important to add that the computation of the proper standard errors for fuzzy measures would require information about the primary sampling units, rotational groups and strata from the EQLS survey that is not available. Therefore, the implemented Dunn's test must be considered a straightforward, although crude, method of overcoming the lack of more appropriate information.

The findings on $\mathrm{FW}$ overall suggest that northern countries have the highest levels of FW, and they do not differ from each other, but they are significantly different from many other countries. By contrast, Cyprus and Greece show the lowest degree of $\mathrm{FW}_{\text {OVERALL}}$, and their level of FW is significantly different from the other countries. Germany is positioned at the top of the ranking and shows a significant difference from France, and it is different from the Mediterranean countries (Italy included). On the other hand, France does not show a significant difference from Italy. Finally, although the remaining countries have different levels of FW, they generally do not show statistically significant differences.

To obtain a clear and effective synthesis of findings, considering the five dimensions of FW, we use a cluster analysis. We use an agglomerative hierarchical algorithm to identify groups of countries with some degree of similarity (Everitt and Dunn, 1991). This technique separates each case into its own individual cluster in the first step so that the initial number of clusters equals the total number of cases (Norusis, 2010). At successive steps, similar cases, or clusters, are merged together until every case is grouped into one single cluster. The proximity between clusters was calculated using both complete linkage and Ward's method. To determine the appropriate number of clusters, we observe the $R^{2}$ index, the increase in the coefficient values in the distance between two clusters (or cases) joined at each stage and the Elbow criterion in the structure diagram between the proximity coefficients and the number of clusters. As such, the number of clusters is a compromise between simplification and homogeneity. The findings $\left(R^{2}=0.6\right.$; a sudden jump in the distance coefficient of 0.13 and an
Measuring financial well-being 


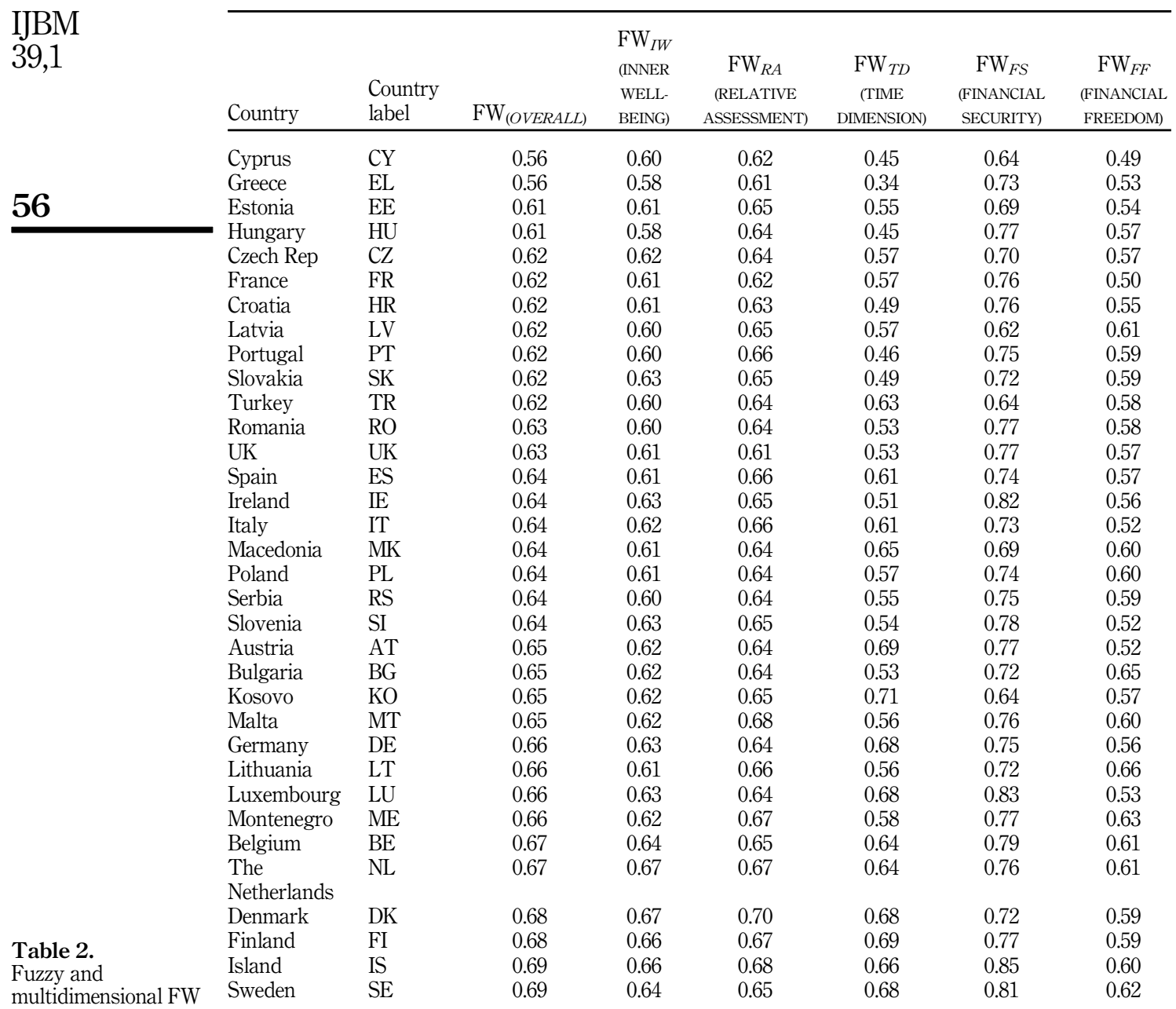

Note(s): The countries have been listed from the lowest to the highest value of FW overall index

elbow in the graph) suggest a classification into five groups. Moreover, the Rand index (Rand, 1971) was calculated between the complete linkage algorithm and Ward's method to evaluate the stability of the classification. The value of 0.84 denotes strong agreement between the two classifications.

Table 3 summarizes the classification obtained through Ward's clustering algorithm. In the table, we report the size of each cluster, its composition and the mean of the fuzzy measures in each dimension of FW.

The findings suggest that time $\left(R^{2}=0.85\right)$, financial security $\left(R^{2}=0.67\right)$ and inner wellbeing $\left(R^{2}=0.62\right)$ are the dimensions that have the most explanatory power as measured by the $R^{2}$ index. In other words, these three dimensions are likely to be the dimensions that contribute most to differences in the FW index.

In particular, Cyprus and Greece are the countries characterized by the lowest average values in four dimensions out of five. By contrast, the northern countries, together with 


\begin{tabular}{|c|c|c|c|c|c|c|}
\hline Cluster & 1 & 2 & 3 & 4 & 5 & Measuring \\
\hline Size & 4 & 10 & 2 & 9 & 9 & financial \\
\hline Composition & $\begin{array}{l}\text { Kosovo, } \\
\text { Latvia, } \\
\text { Macedonia, } \\
\text { Turkey }\end{array}$ & $\begin{array}{l}\text { Bulgaria, Czech } \\
\text { Republic, Estonia, } \\
\text { Italy, Lithuania, } \\
\text { Malta, Montenegro, } \\
\text { Poland, Serbia, } \\
\text { Spain }\end{array}$ & $\begin{array}{l}\text { Cyprus, } \\
\text { Greece }\end{array}$ & $\begin{array}{l}\text { Croatia, France, } \\
\text { Hungary, } \\
\text { Ireland, } \\
\text { Portugal, } \\
\text { Romania, } \\
\text { Slovakia, } \\
\text { Slovenia, the } \\
\text { UK }\end{array}$ & $\begin{array}{l}\text { Austria, Belgium, } \\
\text { Denmark, Finland, } \\
\text { Germany, Island, } \\
\text { Luxembourg, The } \\
\text { Netherlands, } \\
\text { Sweden }\end{array}$ & well-being \\
\hline $\begin{array}{l}\mathrm{FW}_{I W} \text { (Inner } \\
\text { Well-being) }_{2} \\
{ }^{2} \\
0.62\end{array}$ & 0.61 & 0.61 & 0.59 & 0.61 & 0.65 & \\
\hline $\begin{array}{l}\mathrm{FW}_{R A} \text { (Relative } \\
\text { Asssessment) }_{2} \\
R \\
0.38\end{array}$ & 0.65 & 0.65 & 0.62 & 0.64 & 0.66 & \\
\hline $\begin{array}{l}\mathrm{FW}_{T D} \text { (Time } \\
\text { Dimension) }_{2} \\
R^{2} \\
0.85\end{array}$ & 0.64 & 0.57 & 0.40 & 0.51 & 0.67 & \\
\hline $\begin{array}{l}\mathrm{FW}_{F S} \\
\text { (Financial } \\
\text { Security) } \\
2 \\
R\end{array}$ & 0.65 & 0.73 & 0.69 & 0.77 & 0.78 & \\
\hline $\begin{array}{l}0.67 \\
\mathrm{FW}_{F F} \\
\text { (Financial } \\
\text { Freedom) } \\
{ }_{2} \\
0.28\end{array}$ & 0.51 & 0.59 & 0.51 & 0.56 & 0.58 & $\begin{array}{r}\text { Table } 3 . \\
\text { Cluster size, } \\
\text { composition and the } \\
\text { mean of fuzzy } \\
\text { measures in each } \\
\text { dimension }\end{array}$ \\
\hline
\end{tabular}

Germany, Austria, Belgium, The Netherlands and Luxembourg, form a cluster characterized by the highest levels in all the dimensions, except for $\mathrm{FW}_{F F}$. Moreover, the first cluster composed of Kosovo, Latvia, Macedonia and Turkey is characterized by the lowest value in the $\mathrm{FW}_{F S}$ dimension. The other two groups of countries substantially differ in their average values in the $\mathrm{FW}_{T D}$ and $\mathrm{FW}_{F S}$ dimensions. In particular, in the cluster that includes France, the UK, Ireland, Portugal and some Eastern European countries, we observe a low average value in the $\mathrm{FW}_{T D}$ dimension and a high average value in the $\mathrm{FW}_{F S}$ dimension, which is in contrast to the group that includes Italy, Spain, Malta and some other eastern countries. In summary, it seems that the dimension of financial security clearly separates these two last clusters.

Further interesting findings arise when we explore the fuzzy measures at the country level in relation to important socio-economic and demographic characteristics, as suggested by different contributions of the FW literature (see, e.g. Van Praag et al., 2003: Arber et al., 2014; Sass et al., 2015; CFPB, 2015; Brüggen et al., 2017). In particular, we consider the following: (1) household income (i.e. people in the last quartile of the income distribution vs people in the first quartile of the income distribution), (2) employment status (i.e. people working vs people not working), (3) level of education (high level vs low level) and (4) gender (male vs female).

The results are summarized in Figure 1.

As such, the income analysis shows that the highest levels of family income (i.e. up to the fourth quartile of the income distribution) are accompanied by the highest levels of FW (e.g. 
IJBM

39,1

58
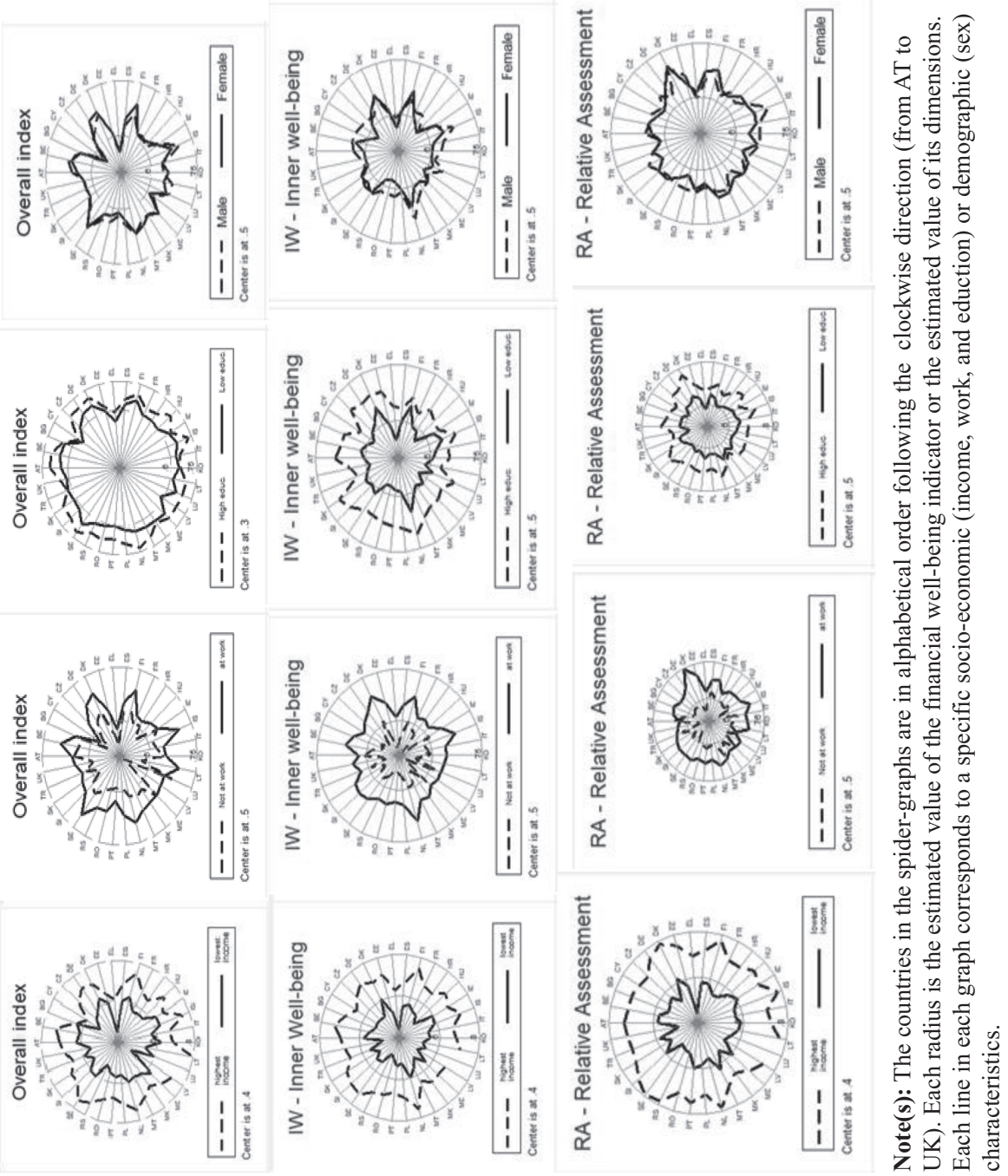

Figure 1.

Fuzzy indicator of FW
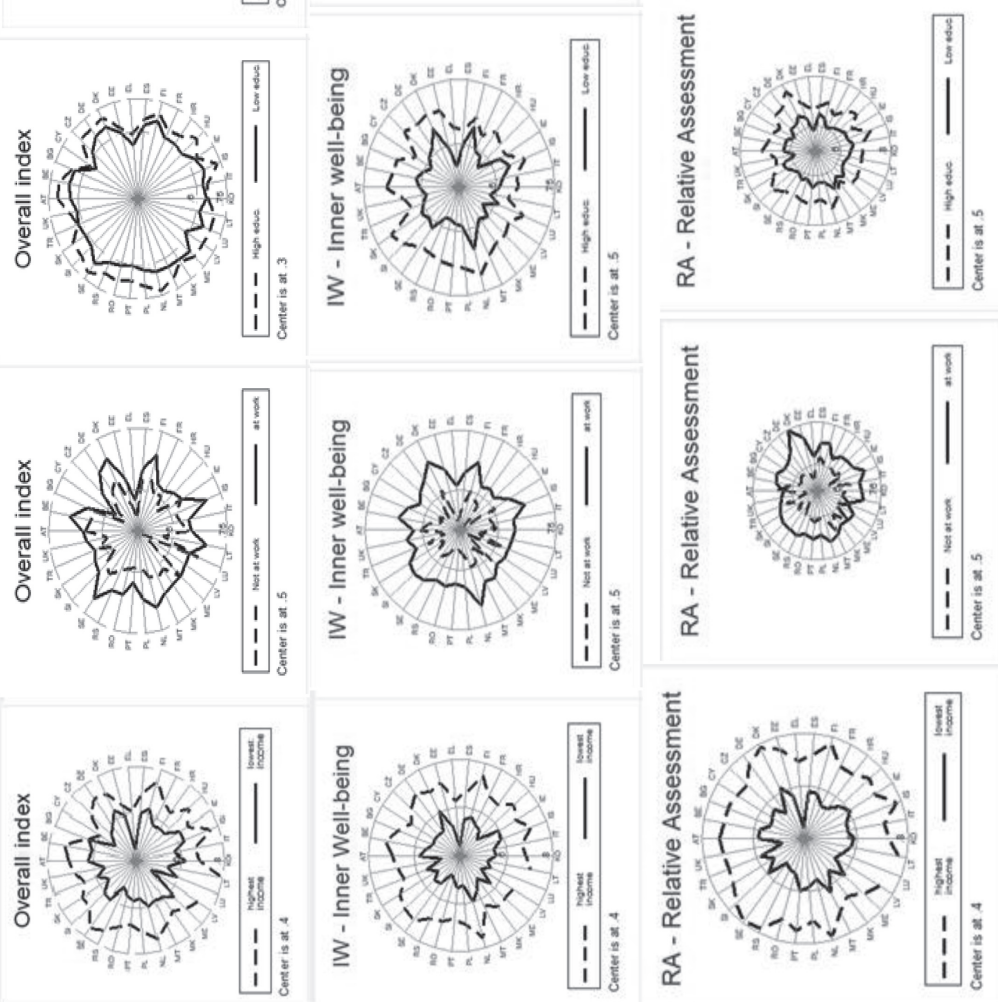

के च्ञ

毒吉

के

三 굴

讶

$\exists=$

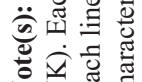

by socio-economic and demographic

characteristics 
Measuring financial well-being
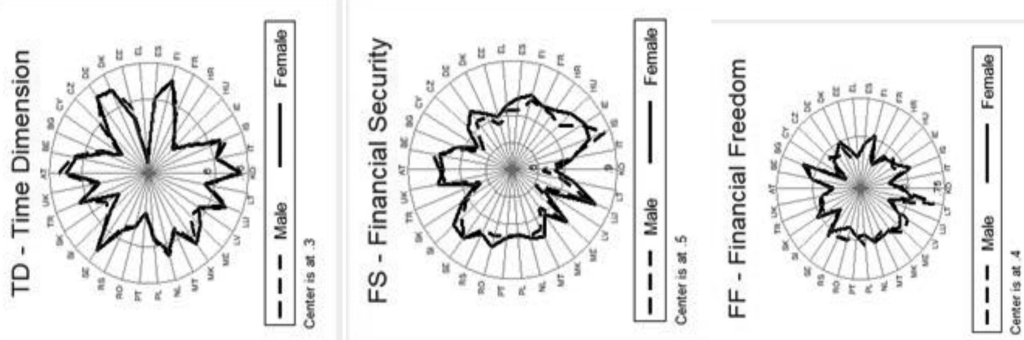

59
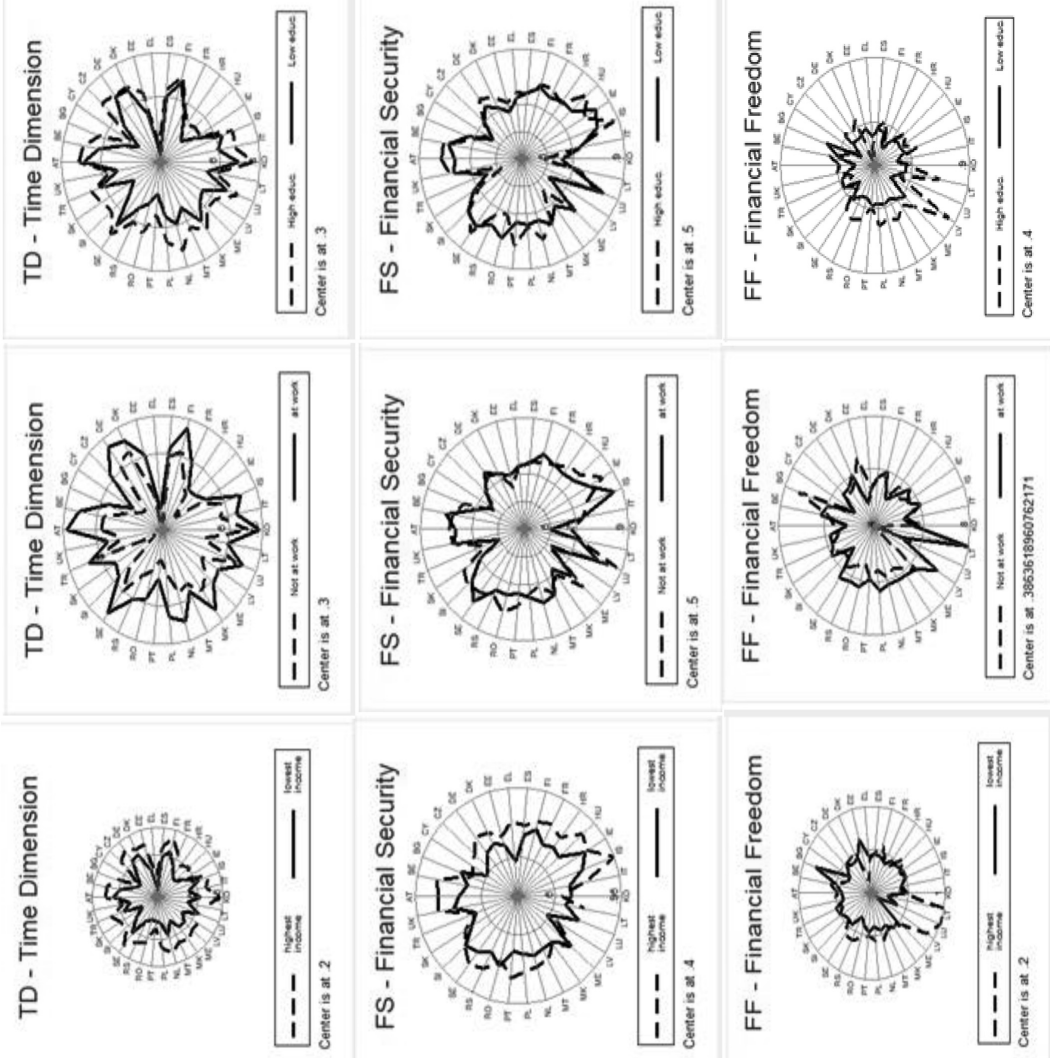

Figure 1. 
IJBM

39,1

60

Chatterjee et al., 2019). If the gaps are more pronounced for the global index and for the inner and relative dimensions, the distance is attenuated for the other dimensions (with the exception of financial freedom in some post-communist countries where the gap remains wide).

Regarding working conditions, it appears that for most countries, better working conditions are accompanied by better FW, but there are also cases in which the gap in FW between those working and those not working vanishes, as in Austria, Ireland, Montenegro, or in which it even reverses, as in Luxembourg.

With regard to education, the highest levels of education are accompanied by the highest levels of FW. This evidence is more marked for the inner and relative dimensions. On the other hand, there are slight or even no differences for $\mathrm{FW}_{T D}$ and $\mathrm{FW}_{F S}$ in many countries. Finally, the dimension of $\mathrm{FW}_{F F}$ shows rather wide gaps in Latvia and Lithuania.

Finally, it seems that women place greater emphasis, for better (i.e. Finland) or worse (i.e. Cyprus), on the perception of FW than men by showing a greater sensitivity to economic issues when answering the survey questions. This evidence on the gender gap is consistent across all dimensions of $\mathrm{FW}$.

\section{Discussion and conclusions}

Applying the fuzzy approach to assess the multidimensional phenomenon of $\mathrm{FW}$ in Europe leads to some interesting considerations.

First, FW is heterogeneous across European countries, but it is possible to identify two different groups that can be seen as two "poles" of FW: on the one hand, the northern countries and, on the other hand, the southern countries. Indeed, the levels of FW in Northern European countries (i.e. Denmark, Finland, Iceland and Sweden) are consistent with their traditional levels of social rights and quality of life (Esping Andersen, 1990; Aiginger and Leoni, 2009). By contrast, the lower level of FW in Mediterranean countries is in line with the literature on poverty (Ciani et al., 2018); from this point of view, it could be interesting to determine if this indication has any relation with the threat of Greece's exit from the Euro area (the "Grexit" dates back to 2011). The findings from the cluster analysis allow us to show how European continental countries compare in terms of FW: Germany belongs to the North "pole" of FW, whereas France and the UK show some issues, especially regarding the time dimension. For example, the protests in the banlieues, the suburbs of the French cities and the protests of the so-called yellow vests can be considered signs of unequal distribution of financial resources within the French population [1] In the UK, the crisis of the Labor Party can be considered a signal of the inability to deal with workers' income distribution requests [2]. Italy also shows some issues. It is in a cluster together with Spain, Malta, Poland and some post-communist countries, showing the lowest percentage of financially literacy and the largest gender gap in financial literacy among the G20 (Hasler and Lusardi, 2017). Regarding post-communist countries, Montenegro has been defined as an economic standout among the countries of South-Eastern Europe (i.e. Albania, Bosnia and Herzegovina, Kosovo, the Former Yugoslav Republic of Macedonia, Montenegro and Serbia), as the gross national income has significantly increased over the past several years, per capita income is the highest among the six countries and poverty has diminished, showing relatively moderate income inequality (Mitra et al., 2010; World Bank, 2014).

Second, the degree of FW also differs along some dimensions. For example, the values of the $\mathrm{FW}_{I W}$ dimension, which is related to individual perceptions of conditions that may affect $\mathrm{FW}$, span from the lowest values, found in the Mediterranean countries, to the highest, in Northern Europe. The $\mathrm{FW}_{T D}$, which is the dimension related to expectations, has some surprises in its low values, e.g. in the UK and France together with some East European countries. This result is emphasized by the moderate value of $\mathrm{FW}_{F F}$ for the same group of 
countries. Regarding $\mathrm{FW}_{F S}$ - the dimension of financial security related, e.g. to the management of credit and debts - the group of the most vulnerable countries is composed of Kosovo, Latvia, Macedonia and Turkey.

Third, this analysis sheds light on the gender gap from the point of view of FW. One explanation of the differences between genders could be related to gender inequalities in social rights, the world of work (i.e. wage differences) and/or the level of financial education (e.g. Potrich et al., 2018). To the best of our knowledge, there are no other studies that provide evidence of gender differences in FW for European countries. Therefore, the financial industry should consider gender differences when developing financial services (i.e. services that are different from certain insurance services that provide coverage for biometric risks or some types of underwriting risks).

Fourth, the results show that there is no obvious correspondence between the level of FW and economic conditions of a country. For instance, the different behavior of Germany or of the UK and France in terms of FW suggests that there is not a clear relationship between the classification of the countries based on their wealth (measured by the gross domestic product (GDP) and/or GDP growth) and their degree of FW. This evidence is in line with the results from the literature on happiness and on quality of life (Easterlin, 1973; Fischer, 2010): wellbeing measured in terms of financial wealth is not directly linked to well-being measured in terms of happiness or quality of life, as increased wealth has an impact on subjective wellbeing only if consumers are poor or live in a developing country (Diener and Biswas-Diener, 2002; Eurofound, 2013).

Further relationships can be deducted by observing other macro-economic indicators beyond the GDP. For instance, northern countries with similarities in governance (e.g. as measured by some World Governance Indicators, such as Control of Corruption, Government Effectiveness, Political Stability and Absence of Violence/Terrorism, Regulatory Quality, Rule of Law and Voice and Accountability) (World Bank, 2010, 2018) and culture (as measured by Government Expenditure in Cultural Services, see Eurostat, 2012) also share very similar levels of FW. By contrast, France and Germany, which are characterized by high values for cultural, social and economic indicators, are different in their levels of FW. This difference is especially evident along the dimension of $\mathrm{FW}_{R A}$, which catches the "relative" dimension of $\mathrm{FW}$, as measured through the comparison of personal conditions with those in the same membership class, which could be friends, classmates or, more simply, one's own personal life goals. It is also evident along the dimension of $\mathrm{FW}_{F F}$, which measures the "degree of freedom" from financial constraints (CFPB, 2015; Brüggen et al., 2017).

As such, the results of the analysis suggest some reasonable implications for policy makers and financial institutions.

To improve FW, especially in those countries where the FW score is low, policy makers could use public spending, which is the most important component of economic policy, or structural reforms in those countries where the ratio between the public debt and the GDP is high. From this perspective, a policy aiming to reduce the unemployment rate, especially among youth, may ameliorate the perception of $\mathrm{FW}$ as it acts on long-term perspectives and on peer-to-peer comparisons (rather than the financial benefits for the specific recipients of public interventions). For example, the Youth Employment Support (YES), which is a package of measures proposed by the European Legislator to increase opportunities for the next generation to take part in green and digital transitions (€22bn), or Support to mitigate Unemployment Risks in an Emergency (SURE), which is an instrument to protect jobs and workers affected by the coronavirus pandemic ( $€ 100 \mathrm{bn})$, may have an impact on the future perception of FW among European citizens.

On the other hand, policy makers could improve FW, especially the financial security and the relative assessment dimensions, by monitoring the FW of their people. For example, Vlaev and Elliott (2014) suggest that the government use an FW index. More specifically, the 
IJBM 39,1

\section{2}

government might require evidence that the products/services banks offer are increasing $\mathrm{FW}$ by using an FW index, especially in countries where there are some fully or partially nationalized banks. Indeed, the European supervisors prefer to focus on financial firms' policies and practices to ensure that vulnerable groups of consumers are not put at risk by poor firm conduct (Deloitte, 2019).

The results herein can also be seen as a laboratory test that could lead financial institutions to call for information. These institutions could use the information on FW to tailor the financial services that they provide. On the other hand, digitalization provides the opportunity to move from a one-size-fits-all approach to a mass personalization of services within the financial industry (Deloitte, 2015). For example, FinTech companies, unlike traditional banks, tailor their processes (thanks to Big Data and machine learning) to provide individual solutions to each consumer (Breidback et al., 2019). A useful way to take advantage of technology to personalize a financial solution could be to provide an assessment of $\mathrm{FW}$ and then an overview of tools that could be used to ameliorate one's own well-being. Indeed, thanks to digitalization, it could be possible to identify a set of tools for each domain of FW. For example, to secure a financial future, the tools could illustrate the advantages of retirement solutions or of other risk management solutions and how a cognitive driver, such as poor knowledge of risk levels (Estelami, 2009), can lead to a suboptimal financial decision. To improve the domain of financial freedom, the tools could classify expenses, allowing the individual to take more control over her/his spending and to identify the budget for extra spending. Indeed, it could be possible to create sub-accounts for all goals (e.g. a travel, a new TV, etc.) and keep them all together and under control thanks to an application such as N26, for example. To increase a sense of one's own finances, the tools may ask to auto-assess FW every time that the customer wants to access her/his own financial resources. To avoid the overload of short-term memory (Estelami, 2009) and to enhance the perception of one's current financial status and of the comparison between objectives and outcomes, the tools might offer monthly check-ups, highlighting the differences between one month and another as well as opportunities to save for the future.

Finally, from the point of view of institutions concerned with implementing financial literacy programs to improve the level of savings rates, it is necessary to identify vulnerable groups in terms of FW.

This study is not free from limitations, which also suggest room for further research on FW. First, we use a large dataset on the quality of life in Europe. To improve our knowledge of $\mathrm{FW}$, it would be useful to invest in a comparison across datasets from different countries.

Second, we control for governance and cultural characteristics. In this regard, we believe that future research may extend our investigation to other countries with different governance and cultural frameworks to detect differences and similarities in FW.

Finally, examining how financial settings at the country level create different degrees of FW should be another area of continued future research.

\section{Notes}

1. https://www.theguardian.com/commentisfree/2011/nov/01/france-debate-class-islam-banlieues.

2. https://www.independent.co.uk/voices/winter-of-discontent-jeremy-corbyn-trade-unions-margaretthatcher-a8741256.html.

\section{References}

Abrantes-Braga, F.D. and Veludo-de-Oliveira, T. (2019), "Development and validation of financial wellbeing related scales", International Journal of Bank Marketing, Vol. 37 No. 4, pp. 1025-1040.

Aggarwal, S. (2014), "Developing an index for measuring financial well-being in a geography", IFMR Finance Foundation, available at: https:/www.dvara.com/blog/2011/02/14/developing-an-indexfor-measuring-financial-well-being-in-a-geography/. 
Aiginger, K. and Leoni, T. (2009), "Typologies of social models in Europe”, available at: http://karl. aiginger.wifo.ac.at/leadmin/les_aiginger/publications/2008/GEMSE_nal.pdf.

Anderson, R., Dubois, H., Leončikas, T. and Sándor, E. (2012), "Quality of life in Europe: impacts of the crisis", Eurofound, Publications Office of the European Union, Luxembourg, doi: 10.2806/42471.

Measuring financial well-being

Arber, S., Fenn, K. and Meadows, R. (2014), "Subjective financial well-being, income and health inequalities in mid and later life in Britain", Social Science and Medicine, Vol. 100, pp. 12-20.

Arnett, J.J. (2000), "Emerging adulthood: a theory of development from the late teens through the twenties", American Psychologist, Vol. 55 No. 5, pp. 469-480.

Bandura, R. (2011), Composite Indicators and Rankings: Inventory 2011, Office of Development Studies, United Nations Development Programme (UNDP), New York.

Betti, G. and Verma, V. (2008), "Fuzzy measures of the incidence of relative poverty and deprivation: a multi-dimensional perspective”, Statistical Methods and Applications, Vol. 12 No. 2, pp. 225-250.

Betti, G., Cheli, B., Lemmi, A. and Verma, V. (2006), "On the construction of fuzzy measures for the analysis of poverty and social exclusion", Statistica and Applicazioni, Vol. IV No. 1, pp. 1-21.

Betti, G., Soldi, R. and Talev, I. (2016), "Fuzzy multidimensional indicators of quality of life: the empirical case of Macedonia”, Social Indicators Research, Vol. 127 No. 1, pp. 39-53.

Betti, G., D’Agostino, A., Ghellini, G. and Longobardi, S. (2020a), "Measuring the impact of financial crisis on quality of life in Europe", Economics Bulletin, Vol. 40 No. 1, pp. 292-307.

Betti, G., D'Agostino, A., Gagliardi, F. and Giusti, C. (2020b), "The integrated fuzzy and relative index for poverty analysis: a review of applications in the social sciences", Studies of Applied Economics, Vol. 38 No. 1.

Breidbach, C.F., Keating, B.W. and Lim, C. (2019), "Fintech: research directions to explore the digital transformation of financial service systems", Journal of Service Theory and Practice, Vol. 30 No. 1, pp. 79-102.

Brüggen, E., Hogreve, J., Holmlund, M., Kabadayi, S. and Lofgren, M. (2017), "Financial well-being: a conceptualization and research agenda", Journal of Business Research, Vol. 79, pp. 228-237.

Chatterjee, D., Kumar, M. and Dayma, K.K. (2019), "Income security, social comparisons and materialism”, International Journal of Bank Marketing, Vol. 37 No. 4, pp. 1041-1061.

Chisholm, L. and Hurrelmann, K. (1995), "Adolescence in modern Europe. Pluralized transition patterns and their implications for personal and social risks", Journal of Adolescence, Vol. 18 No. 2, pp. 129-158.

Ciani, M., Gagliardi, F., Riccarelli, S. and Betti, G. (2018), "Fuzzy measures of multidimensional poverty in the mediterranean area: a focus on financial dimension", Sustainability, Vol. 11 No. 1, p. 143, doi: 10.3390/su11010143.

Comerton-Forde, C., Ip, E., Ribar, D.C., Ross, J., Salamanca, N. and Tsiaplias, S. (2018), Using Survey and Banking Data to Measure Financial Wellbeing, Commonwealth Bank of Australia and Melbourne Institute, available at: https://fbe.unimelb.edu.au/_data/assets/pdf_file/0010/ 2839429/CBA_MI_Tech_Report_No_1.pdf.

Consumer Financial Protection Bureau (CFPB) (2015), Measuring Financial Well-Being. A Guide to Using the CFPB Financial Well-Being Scale, available at: https://www.consumerfinance.gov/ data-research/research-reports/financial-well-being-scale/.

Cronbach, L.J. (1951), "Coefficient alpha and the internal structure of tests", Psychometrika, Vol. 16 No. 3, pp. 297-334.

Deloitte (2015), "The Deloitte consumer review. Made-to-order: the rise of mass personalization", available at: https://www2.deloitte.com/content/dam/Deloitte/ch/Documents/consumerbusiness/ch-en-consumer-business-made-to-order-consumer-review.pdf.

Deloitte (2019), "Ten years on from the crisis. Financial markets regulatory outlook 2019", available at: https://www2.deloitte.com/uk/en/pages/financial-services/articles/emea-financial-marketsregulatory-outlook-predictions-2019.html?id=gb:2or:3dn:4RegOutlook:5awa:6fs:PDFpg3. 
IJBM

39,1

Diener, E. and Biswas-Diener, R. (2002), “Will money increase subjective well-being?”, Social Indicators Research, Vol. 57 No. 2, pp. 119-169, doi: 10.1023/A:1014411319119.

Dinno, A. (2015), “Nonparametric pairwise multiple comparisons in independent groups using Dunn's test”, The Stata Journal: Promoting Communications on Statistics and Stata, Vol. 15 No. 1, pp. 292-300, doi: 10.1177/1536867X1501500117.

D'Agostino, A., Gagliardi, F., Giusti, C. and Potsi, A. (2019), "Investigating the impact of the economic crisis on children's wellbeing in four European countries", Social Science Research, Vol. 84 November, pp. 1-15.

Easterlin, R.A. (1973), "Does money buy happiness?", The Public Interest, Vol. 30, pp. 3-10.

Esping-Andersen, G. (1990), The Three Worlds of Welfare Capitalism, Polity Press, Cambridge.

Estelami, H. (2009), "Cognitive drivers of suboptimal financial decisions: implications for financial literacy campaigns”, Journal of Financial Services Marketing, Vol. 13 No. 4, pp. 273-283.

Eurofound (2013), Third European Quality of Life Survey - Quality of Life in Europe: SubjectivewellBeing, Publications Office of the European Union, Luxembourg, available at: https://www. eurofound.europa.eu/it/publications/report/2013/quality-of-life-social-policies/quality-of-life-ineurope-subjective-well-being.

Eurostat (2012), Culture Statistics- Government Expenditure on Culture, available at: https://ec.europa. eu/eurostat/statistics-explained/index.php?title=Culture_statistics_-_government_ expenditure_on_culture.

Everitt, B.S. and Dunn, G. (1991), Applied Multivariate Data Analysis, John Wiley and Sons, New York, NY.

Figari, F., Matsaganis, M. and Sutherland, H. (2011), "The financial well-being of older people in Europe and the redistributive effects of minimum pension schemes", EUROMOD, Working Paper No. EM7/11, available at: https://www.econstor.eu/bitstream/10419/64883/1/ 68500712X.pdf.

Fisher, C.D. (2010), "Happiness at work", International Journal of Management Reviews, Vol. 12 No. 4, pp. 384-412, doi: 10.1111/j.1468-2370.2009.00270.x.

Florendo, J. and Estelami, H. (2019), "The role of cognitive style, gullibility, and demographics on the use of social media for financial decision making", Journal of Financial Services Marketing, Vol. 24 Nos 3-4, pp. 1-10, doi: 10.1057/s41264-019-00064-7.

Giambona, F. and Vasallo, E. (2014), "Composite indicator of social inclusion for European countries", Social Indicators Research, Vol. 116, pp. 269-293.

Greco, S., Ishizaka, A., Tasiou, M. and Torrisi, G. (2019), "On the methodological framework of composite indices: a review of the issues of weighting, aggregation, and robustness", Social Indicators Research, Vol. 141 No. 1, pp. 61-94, doi: 10.1007/s11205-017-1832-9.

Greninger, S.A., Hampton, V.L., Kitt, K.A. and Achacoso, J.A. (1996), "Ratios and benchmarks for measuring the financial well-being of families and individuals", Financial Services Review, Vol. 5 No. 1 , pp. 57-70.

Grupp, H. and Mogee, M.E. (2004), "Indicators for national science and technology policy: how robust are composite indicators?", Research Policy, Vol. 33 No. 9, pp. 1373-1384.

Hasler, A. and Lusardi, A. (2017), The Gender Gap in Financial Literacy: A Global Perspective, available at: https://gflec.org/wp-content/uploads/2017/07/The-Gender-Gap-in-Financial-Literacy-AGlobal-Perspective-Report.pdf?x87657.

Hoyle, R.H. and Panter, A.T. (1995), "Writing about structural equation models", in Hoyle, R.H. (Ed.), Structural Equation Modelling: Concepts, Issues, and Applications, Sage Publications, Thousand Oaks, CA, pp. 158-176.

Hu, L. and Bentler, P. (1995), "Evaluating model fit", in Hoyle, R.H. (Ed.), Structural Equation Modelling. Concepts, Issues, and Applications, Sage Publications, Thousand Oaks, CA, pp. 76-99. 
International Monetary Fund (IMF) (2014), World Saving, available at: https://www.imf.org/en/ Publications/WP/Issues/2016/12/31/World-Saving-42452.

Kabadayi, S. and O'Connor, G.E. (2019), "Guest editorial”, International Journal of Bank Marketing, Vol. 37 No. 4, pp. 930-933, doi: 10.1108/IJBM-06-2019-338.

Measuring financial well-being

Kaklauskas, A., Zavadskas, E.K., Radzeviciene, A. and Bučinskas, V. (2018), "Quality of city life multiple criteria analysis", Cities, Vol. 72, pp. 82-93, doi: 10.1016/j.cities.2017.08.002.

Kempson, E., Finney, A. and Poppe, C. (2017), "Financial well-being. A conceptual model and preliminary analysis", Consumption Research Norway, SIFO, Project Note No. 3-2017, Final ed.

Kline, R.B. (2005), Principles and Practice of Structural Equation Modelling, 2nd ed., Guilford Press, New York, NY.

LaRochelle-Côté, S. (2012), "Financial well-being in retirement", Analytical Paper, Economic Insights, Catalogue no. 11-626-X, no. 014, Statistics Canada, available at: https://www150.statcan.gc.ca/ n1/en/pub/11-626-x/11-626-x2012014-eng.pdf?st=ww-STmpc.

Mitra, P., Selowsky, M. and Zalduendo, J. (2010), Turmoil at Twenty: Recession, Recovery, and Reform in Central and Eastern Europe and the Former Soviet Union, World Bank, Washington, DC, pp. 1-275.

Muir, K., Hamilton, M., Noone, J.H., Marjolin, A., Salignac, F. and Saunders, P. (2017), "Exploring financial wellbeing in the AustralianContext", Report for Financial Literacy Australia, Centre for Social Impact and Social Policy Research Centre, University of New South Wales, Sydney.

Netemeyer, R.G., Warmath, D., Fernandes, D. and Lynch, J.G. (2018), "How Am I doing? Perceived financial well-being, its potential antecedents, and its relation to overall well-being", Journal of Consumer Research, Vol. 45 No. 1, pp. 68-89, doi: 10.1093/jcr/ucx109.

Norusis, M.J. (2010), Cluster analysis PASW Statistics 18 Statistical Procedures Companion, Prentice Hall, Upper Saddle River, NJ.

Piumatti, G. (2017), "Relations between longitudinal trajectories of subjective financial wellbeing with self-rated health among elderly", Medicina, Vol. 53 No. 5, pp. 323-330.

Ponchio, M.C., Almeida Cordeiro, R. and Gonçalves, V.N. (2019), "Personal factors as antecedents of perceived financial well-being: evidence from Brazil”, International Journal of Bank Marketing, Vol. 37 No. 4, pp. 1004-1024.

Potrich, A.C.G., Vieira, K.M. and Kirc, G. (2018), "How well do women do when it comes to financial literacy? Proposition of an indicator and analysis of gender differences", Journal of Behavioral and Experimental Finance, Vol. 17, pp. 28-41.

Prawitz, A.D., Garman, E.T., Sorhaindo, B., O’Neill, B., Kim, J. and Drentea, P. (2006), "In charge financial distress/financial well-being scale: development, administration, and score interpretation", Journal of Financial Counselling and Planning, Vol. 17 No. 1, pp. 34-50.

Rand, W.M. (1971), "Objective criteria for the evaluation of clustering methods", Journal of the American Statistical Association, Vol. 66 No. 336, pp. 846-850.

Riitsalu, L. and Murakas, R. (2019), "Subjective financial knowledge, prudent behaviour and income. The predictors of financial well-being in Estonia", International Journal of Bank Marketing, Vol. 37 No. 4, pp. 934-950.

Rindfuss, R.R. (1991), "The young adult years: diversity, structural change, and fertility", Demography, Vol. 28, pp. 493-512.

Sass, S.A., Belbase, A., Cooperrider, T. and Ramos-Mercado, J.D. (2015), "What do subjective assessments of financial well-being reflect? Center for Retirement Research at Boston College", available at: http://crr.bc.edu.

Shim, S., Xiao, J.J., Barber, B.L. and Lyons, A.C. (2009), "Pathways to life success: a conceptual model of financial well-being for young adults", Journal of Applied Developmental Psychology, Vol. 30, pp. 708-723. 
IJBM

39,1

66

Taber, K.S. (2018), "The use of Cronbach's alpha when developing and reporting research instruments in science education”, Research in Science Education, Vol. 48 No. 6, pp. 1273-1296, doi: 10.1007/ s11165-016-9602-2.

Taylor, M., Jenkins, S. and Sacker, A. (2009), "Financial capability and wellbeing: evidence from the BHPS”, Financial Services Authority Occasional Papers in Financial Regulation, available at: www.fsa.gov.uk.

Taylor, M., Jenkins, S. and Sacker, A. (2011), Financial Capability, Income and Psychological Wellbeing, available at: https://www.iser.essex.ac.uk/research/publications/working-papers/iser/201118.pdf.

Van Praag, B.M.S., Frijters, P. and Ferrer-i-Carbonell, A. (2003), "The anatomy of subjective wellbeing", Journal of Economic Behaviour and Organization, Vol. 51, pp. 29-49.

Vlaev, I. and Elliott, A. (2014), "Financial well-being components", Social Indicators Research, Vol. 118 No. 3, pp. 1103-1123, doi: 10.1007/s11205-013-0462-0.

Whelan, C.T., Layte, R., Maitre, B. and Nolan, B. (2001), "Income, deprivation and economic strain: an Analysis is of the European community household panel", European Sociological Review, Vol. 17, pp. 357-372.

World Bank (2010), "The worldwide governance indicators. methodology and analytical issues", Policy Research Working Paper 5430. available at: http://info.worldbank.org/governance/wgi/ index.aspx\#doc.

World Bank (2014), "First insights into promoting shared prosperity in South East Europe", South East Europe Regular Report No. 5, available at: https://openknowledge.worldbank.org/ bitstream/handle/10986/17786/865170WP0P1450000SEE0MAR20140draft4.pdf?sequence = 1\&isAllowed $=\mathrm{y}$.

World Bank (2018), Worldwide Governance Indicators, available at: http://databank.worldbank.org/ data/source/worldwide-governance-indicators\# (accessed July 2018).

Xiao, J.J. and Porto, N. (2017), "Financial education and financial satisfaction: financial literacy, behavior, and capability as mediators", International Journal of Bank Marketing, Vol. 35 No. 5 , pp. 805-817, doi: 10.1108/IJBM-01-2016-0009.

Zurlo, A.K. (2009), "Personal attributes and the financial well-being of older adults: the effects of control beliefs", PARC Working Paper Series, Vol. 27, available at: https://repository.upenn.edu/ parc_working_papers/27/.

\section{Further reading}

Financial Services Authority (FSA) (2005), Measuring Financial Capability: An Exploratory Study, available at: http://www.bristol.ac.uk/media-library/sites/geography/migrated/documents/ pfrc0510.pdf.

Organisation for Economic Co-operation and Development (OECD) (2013), How's Life? 2013: Measuring Well-Being, OECD Publishing, Paris. doi: 10.1787/9789264201392-en.

\section{Corresponding author}

Maria Grazia Starita can be contacted at: starita@uniparthenope.it 
Appendix

Measuring

financial well-being

\begin{tabular}{|c|c|c|c|c|}
\hline Country & $\begin{array}{l}\text { Country } \\
\text { label }\end{array}$ & $\begin{array}{l}\% \text { of individual in age group } 25-65 \text { on the } \\
\text { total sample }\end{array}$ & $\begin{array}{c}\text { \# individuals in age group } \\
25-65 \\
\end{array}$ & \multirow{3}{*}{67} \\
\hline \multicolumn{2}{|l|}{ All countries } & 69 & \multirow{2}{*}{$\begin{array}{r}29,871^{*} \\
758\end{array}$} & \\
\hline Austria & AT & 71 & & \\
\hline Belgium & $\mathrm{BE}$ & 68 & 699 & \\
\hline Bulgaria & $\mathrm{BG}$ & 69 & 636 & \\
\hline Cyprus & $\mathrm{CY}$ & 69 & 716 & \\
\hline Czech Rep & $\mathrm{CZ}$ & 70 & 731 & \\
\hline Germany & $\mathrm{DE}$ & 66 & 1,860 & \\
\hline Denmark & DK & 68 & 711 & \\
\hline Estonia & $\mathrm{EE}$ & 67 & \multirow[b]{2}{*}{679} & \\
\hline Greece & $\mathrm{EL}$ & 68 & & \\
\hline Spain & $\mathrm{ES}$ & 70 & 1,021 & \\
\hline Finland & FI & 67 & 666 & \\
\hline France & FR & 68 & \multirow{2}{*}{$\begin{array}{r}1,566 \\
686\end{array}$} & \\
\hline Croatia & $\mathrm{HR}$ & 69 & & \\
\hline Hungary & $\mathrm{HU}$ & 70 & 701 & \\
\hline Ireland & IE & 72 & 763 & \\
\hline Iceland & IS & 72 & 736 & \\
\hline Italy & IT & 68 & 1,638 & \\
\hline Kosovo & $\mathrm{KO}$ & 69 & \multirow{2}{*}{$\begin{array}{l}786 \\
680\end{array}$} & \\
\hline Lithuania & LT & 65 & & \\
\hline Luxembourg & LU & 72 & 749 & \\
\hline Latvia & LV & 67 & 626 & \\
\hline Montenegro & $\mathrm{ME}$ & 70 & 660 & \\
\hline Macedonia & MK & 71 & 702 & \\
\hline Malta & MT & 67 & 686 & \\
\hline The & NL & 69 & \multirow[t]{2}{*}{693} & \\
\hline \multicolumn{4}{|l|}{ Netherlands } & \\
\hline Poland & PL & 71 & 1,610 & \\
\hline Portugal & $\mathrm{PT}$ & 68 & 629 & \\
\hline Romania & RO & 69 & 1,054 & \\
\hline Serbia & RS & 71 & 739 & \\
\hline Sweden & SE & 67 & 670 & \\
\hline Slovenia & SI & 71 & 684 & \\
\hline Slovakia & SK & 73 & 728 & \\
\hline Turkey & TR & 74 & 1,513 & \\
\hline UK & UK & 69 & 1,496 & Table A1. \\
\hline $\begin{array}{l}\text { Note(s): Hoy } \\
28,239 \text { individ }\end{array}$ & $\begin{array}{l}\text { er, after eli } \\
\text { s }\end{array}$ & ting the observations with missing values, $t$ & e sample size used becomes & $\begin{array}{r}\text { Sample size across } \\
\text { countries }\end{array}$ \\
\hline
\end{tabular}




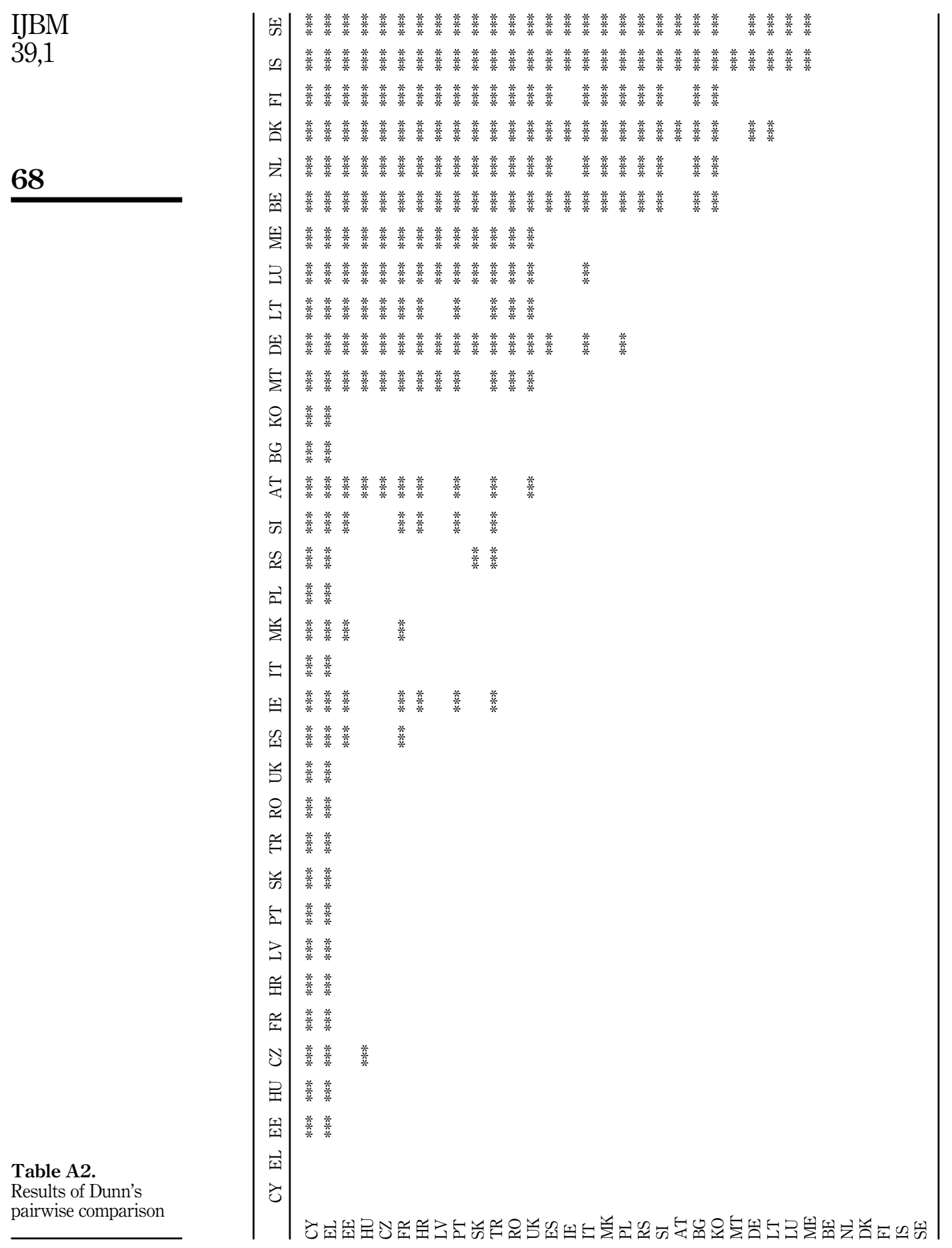

